\title{
Factors that affect social health insurance enrollment and retention of the informal sector in the Philippines: a qualitative study
}

Reneepearl Kim Sales ( $\sim$ ksales@aiho.org.ph )

Alliance for Improving Health Outcomes, Inc. https://orcid.org/0000-0002-6399-4095

Gladys Kaye Reyes

Alliance for Improving Health Outcomes, Inc.

Timothy Ting

Alliance for Improving Health Outcomes, Inc.

Dante Salvador, Jr.

Alliance for Improving Health Outcomes, Inc.

Research article

Keywords: informal sector, health insurance, universal health care, health finance, Philippines, developing country

Posted Date: January 23rd, 2020

DOI: https://doi.org/10.21203/rs.2.21706/v1

License: (9) This work is licensed under a Creative Commons Attribution 4.0 International License. Read Full License 
1 Factors that affect social health insurance enrollment and retention of the informal

2 sector in the Philippines: a qualitative study

3

4 Reneepearl Kim Sales ${ }^{1}$, Gladys Kaye Reyes ${ }^{1}$, Timothy Ting ${ }^{1}$, Dante Salvador, Jr. ${ }^{1}$

$5{ }^{1}$ Alliance for Improving Health Outcomes, 62 West Avenue, West Triangle, Quezon City,

6 Philippines

7

8

9 Corresponding Author:

10 Reneepearl Kim Sales

11 Alliance for Improving Health Outcomes, 62 West Avenue, West Triangle, Quezon City,

12 Philippines

13

ksales@aiho.org.ph

14 Abstract word count: 226

15

Main text word count: 3,684

16

17

18

19

20

21

22 


\section{Abstract}

25 Background. The primary goal of providing social protection to informal sector workers is to guarantee a minimum level of income and dignity that allows for better protection against income shocks and other vulnerabilities. With the passage of the Universal Health Care Act in the Philippines, the determination of factors affecting enrollment and retention into social health insurance among informal sector workers in the Philippines is crucial to design appropriate policies and programs fit to their needs.

Methods. This study aimed to identify factors that affect social health insurance enrollment and retention of the informal sector in the Philippines through qualitative research methods of face-to-face, semi-structured focus group discussion and key informant interviews.

Results. The analysis identified five broad themes that affect informal sector enrollment and retention in social health insurance: 1) overlaps in categorization, 2) insufficient or inappropriate social health insurance initiatives for the informal sector, 3) awareness and understanding of social health insurance, 4) supply side factors, and 5) convenience and amount of premium payment.

Conclusion. Informal workers are individuals who are not covered by protective labor laws and tend to not belong or contribute to a national health insurance scheme. In the case of the Philippines, the diversity of informal work and dynamic nature of the sector works against an ideal one-size-fits-all solution to increasing informal sector enrollment and retention to social health insurance.

Keywords: informal sector, health insurance, universal health care, health finance, Philippines, developing country 


\section{Background}

50 Since its establishment in 1995 through the National Health Insurance Act, the Philippine

51 Health Insurance Corporation has developed various strategies in ensuring universal health

52 care $(\mathrm{UHC})$. This is complemented by national health policies which guarantee Filipinos equitable access to quality and affordable health goods and services. The recently signed UHC Law "guarantees all Filipinos equitable access to quality and affordable health goods and services and protected against financial risk protection". With its implementation, Filipino citizens will either be indirect contributors (sponsored, subsidized by the government) or direct contributors. Efforts of developing countries like the Philippines to expand health coverage are characterized by a common enrollment and financing pattern: commencing with formal sector workers followed with government-subsidized enrollment of the poor (2). The informal sector group is typically left behind which then makes them vulnerable to health catastrophes.

The International Labor Organization describes the work undertaken by informal laborers as any economic activity undertaken by workers and profitable units that are not legally or sufficiently recognized by formal arrangement (3). The Philippine Department of Labor and Employment estimates that in $2017,22.71$ million individuals or $56 \%$ of the total employed population were in the informal sector (4). The sector is identified as the "missing middle" whose membership and retention to a national health insurance program is crucial to attain UHC. They are some of the most mobile and volatile members of the Philippine social health insurance (SHI), influenced by a multitude of factors that affect voluntary payment options. To date, just over $27 \%$ (6.3 million) of informal sector members in the Philippines are registered to $\mathrm{SHI}$ and only $1 \%$ (2.4 million) are actively paying members. This translates into a $\$ 959$ million annual premium loss for the country (5).

The primary goal of providing social protection to informal sector workers is to guarantee a minimum level of income and dignity that allows for better protection against income shocks and other vulnerabilities (1). With the passage of the UHC Act, determination of factors 
affecting enrollment and retention into $\mathrm{SHI}$ of the informal sector in the Philippines is crucial to design appropriate policies and programs fit to their needs.

77

78

79

80

81

82

\section{Methods}

This study aimed to identify factors that affect SHI enrollment and retention of the informal sector in the Philippines through face-to-face, semi-structured focus group discussion and key informant interviews.

\section{Sampling and participants}

This study used convenience, purposive, and snowball sampling to select study participants. For key informant interviews, participants from government and non-government agencies were targeted through an online search of department heads and key leaders. Critical employees within the agencies were chosen based on their roles and its relevance to the informal sector. Recommendations by other targeted participants as well as authors of published literature on informal sector in the Philippines were also invited to participate in the study. Informal sector participants for the focus group discussion were recruited through unions.

The targeted participants were contacted via letter of invitation, e-mail, text messages, and phone calls. Out of the 35 potential participants, 16 participated in key informant interviews and six informal sector workers joined the focus group discussion. No response was received from three potential key informants while one was not able to participate due to scheduling conflicts. Due to the precarious nature of their work, four informal sector representatives were unable to join the focus group discussion.

\section{Setting and data collection}

A topic guide was developed by the researchers in preparation for the interviews and focus group discussion. The topic guide was based on important points to cover during the interview 
or discussion based on literature review. The topic guide was not pilot tested but was refined

100 after each interview and discussion.

101 A total of 16 key informant interviews and one focus group discussion were conducted in 102 meeting rooms or offices. Before beginning each interview and focus group discussion, the researchers introduced themselves and the participants were oriented on the research purpose, objectives, its funder, the purpose of the interview or discussion, participation risks, right to refuse or end participation, right to retract statement, and confidentiality of their identity and responses. The participants were then asked to sign a written informed consent form.

The interviews and focus group discussion were held between August to September 2019 in Manila, Philippines. Interviews lasted between one to three hours while the focus group discussion ran for four hours. No more than three researchers were present per interview and discussion. All researchers present during the interview or discussion hold post-graduate degrees and have previous experience and training in conducting qualitative research methods. Besides the researchers and participants, no other individuals were present. Interviews and discussions were held in the local language and/or English, depending on the preference of the participants. The interviews and discussion were audio recorded with the consent of the participants. Notes were also taken during the interview by one of the researchers to aid in data collection and analysis. Renumeration was only provided to informal sector workers to replace income lost by attending the discussion. No repeat interviews were carried out.

\section{Analysis}

Iterative, inductive thematic and content analysis was used to synthesize findings. These types of analysis were chosen due to the wide variety of research questions and topics that can be addressed through these methods (6). The transcription of audio recordings was ongoing during the study and were completed between one to four weeks after each interview or discussion. Transcription was done by a 
researcher who was present during the interview or discussion. This was done to achieve

126 familiarity and entirety of the data and allow understanding of phrasing or the meaning of a

127 term within the context of the interview or discussion.

128 The transcribed text was disassembled for thematic analysis using Google Sheets by one 129 researcher. The topic guide was used for initial a priori coding. A second researcher then repeatedly analyzed the transcripts and a priori coded data for grounded coding. Emerging themes and codes were sharpened and refined throughout this period and was done repeatedly until new data did not alter the definition of the themes and codes. Data saturation was declared once no new patterns and themes emerged from the data.

The data were grouped and regrouped continuously to show patterns that may indicate an explanation for factors that affect national health insurance enrolment and retention of the informal sector. Interpretation and conclusion were conducted by one researcher. Interpretation and conclusion were based both in and outside the context of the data. Relationships between the themes was also considered in interpreting the data and drawing conclusions.

Results

The analysis identified five broad themes that affect informal sector enrollment and retention in SHI (Table 1). The findings are discussed in more detail below with examples selected from the dataset indicated between quotation marks.

Table 1. Factors that affect SHI enrollment and retention of the informal sector in the Philippines - Overlaps in categorization

- Insufficient or inappropriate SHI initiatives for the informal sector

- Awareness and understanding of SHI

- Supply side factors: quality of services and current benefits

- Convenience and amount of payment 
148 Informal workers should be categorized as individually paying SHI members. However, 149 overlaps do occur in the system.

150 Due to the variability of work and income in the informal sector, there are near-poor informal workers that can overlap with indigents. Local governments estimate that $90-95 \%$ of their sponsored members are actually informal workers. While local governments may view this as UHC, one informant claimed that this is only universal coverage.

There have been recommendations to remove local government sponsorship due to its politicization and free riding (those with capacity to pay apply to be sponsored). Stringent screening is necessary to identify qualified members, but this is difficult due to lack of social workers in health facilities and shared data between agencies to determine trueness of applicant declaration. An informal worker participant said:

Another informant said:

"There is currently no data sharing amongst government agencies. Enrollees are not required to declare their profession and sources of income and no cross-checking is done on their declaration."

Adverse selection through point-of-service membership also occurs. This was originally intended as a stopgap measure and safety net. However, members now pay at the point-ofservice once they need to avail benefits. This defeats the purpose of an insurance scheme, where funding should be prepaid for planning and investment. A key informant explains this:

"The point-of-service should only be a stop-gap measure and a social safety net. But from a financing perspective, payments should be prepaid so one can plan and invest 
the money. With this, it's spending the money right on the spot without letting it grow and without sharing it within the pool for other people to use."

\section{$\underline{\text { Insufficient or inappropriate SHI initiatives for the informal sector }}$}

There were varied responses regarding current $\mathrm{SHI}$ policies and programs in place for the informal sector. Some informants revealed that there is no specific strategy or program for the informal sector. Because the sector does not comprise the bulk of SHI contributions, there are limited to no marketing plans and funds for the sector. This represents a missed opportunity in engaging informal sector, considering that they are the majority of the working population. One informant said:

"There is no active promotion or advertising for the informal sector. This depends on the region. Radio and television ads are preferred but are very expensive."

While there have been initiatives in some regions for group membership, informants did not find this suitable for the sector due to 1) their unorganized nature, 2) the issue of security once contributions grow, 3) the need to access payment site to pay the contribution. A key informant said:

"Group membership only covers a very small percentage of the informal sector. They're not organized so this is unsuitable for them. Even if pilot tests of group membership were successful, this is difficult to scale up."

When asked why previous initiatives failed, informants cited the lack of 1 ) official receipts of some proposed mechanisms, 2) infrastructure at the time, and 3) political buy-in and leadership. For digital platforms, the changing technical requirements which payment channels are unable to comply with and information technology human resource capacity from $\mathrm{SHI}$ are a barrier to implementation. An informant shared: 
"Group memberships only issue one receipt for the entire group. If one member gets sick, no receipt can be shown as proof of payment. Mobile payments only provide acknowledgement of payment with no official receipt."

Another informant said: they can trust and serve as the link to government but also understands the process."

Informants recommend that $\mathrm{SHI}$ explore marketing strategies in the areas of willingness to invest of informal sector, repackaging the program per segment of the sector, and exploring how private health insurance companies sell their products. Another recommendation is to utilize social media as the primary marketing tool if there are limited marketing funds for the informal sector. Finally, it is recommended to relax the requirements to be a collecting agent and address the issue of interrupted contribution periods, a common phenomenon for seasonal workers.

\section{Awareness and understanding of SHI}

Results from interviews and focus group discussions show that enrollment is primarily affected by how members of the informal sector understand SHI. In particular, the concept of SHI in relation to other social insurance schemes is important. Unlike other social insurance schemes wherein return on investment is tangible, $\mathrm{SHI}$ is seen as a riskier investment that, if left unused, translates into wasted money. An informant explained: "People are more interested in an insurance if they know their money will grow. The concept of health insurance is still not clear to many. The concept that people have of $\mathrm{SHI}$ is that it is only used in health emergencies. If the member does not use health services in an emergency, this is interpreted as a wasted investment."

Another informant said: 

"Not everyone sees the value of SHI. It is very hard to see the value of prevention. Other social insurance schemes have a tangible return of investment."

221

An informal worker shared:

"I prioritize payment of other social insurance schemes over health insurance since it offers more benefits with tangible returns."

Reasons for enrollment and retention include availment of benefits or discounts and practicing their rights as workers. Conversely, lack of knowledge on how to enroll, where to pay, and benefits prevent are barriers to enrollment and retention. An informal worker participant said:

"There is appreciation and acceptance of SHI but there is limited knowledge on the amount of payment, where to pay, and the benefits."

\section{Supply-side factors: quality of services and current benefits}

Quality of services also affects retention, with informants less inclined to retain membership if the quality of service they receive both in $\mathrm{SHI}$ and health facilities is poor. One informant explained:

"When the experience in availing services in the health facility is not good, individuals second guess paying for membership. This contributes to the feeling that they are discriminated against, particularly if they are near-poor."

The lack of coverage for outpatient and primary care services, which are the most common services used by informants, discourages them from premium payment. While some medicines are covered by SHI, these are often out-of-stock in public health facilities, thus rendering the membership useless. In addition, when informants apply for SHI reimbursement, the tediously slow process is a deterrent to claim the benefit. An informal worker shared:

"They should provide medications. Currently, medicines purchased outside the health facility are not covered. But health facilities are always out-of-stock." 
244 Informants find the payment of premium to be an inconvenience, citing that payment sites are 245 inaccessible and requires that they take a day off from work. The combined cost of income 246 lost, transportation, and the premium discourages informal workers to pay their contributions on schedule. An informant shared: "Payment mechanisms need to be accessible. There is indirect cost when there is a need to go to the payment site. Access is an issue especially for geographically isolated and disadvantaged areas."

251 Despite high willingness to pay, unaffordability of the premium is also a deterrent to continuous payment, especially when coupled with factors such as seasonality of income and other financial priorities. In particular, informal workers prioritize other social insurance schemes. Interestingly, the high premium for other schemes is the reason cited for not missing a payment schedule. Because of high premiums in other social insurance schemes, carrying over a missed payment to the next cycle is financially damaging to informal workers as this can amount up to almost Php 5,000. This is contrary to the Php 200 monthly premium for SHI, which informants said they can afford to be carried over in the next cycle if missed. An informant said:

"The informal sector is willing to pay but not at the current rate. Formal sector workers only contribute half and share the burden with their employers. Informal workers Interrupted or lapsed contribution occurs if the workers are put in floating status by their shoulder $100 \%$ of the burden of the premium." employer, a state wherein they are unemployed but are retained by their employer with benefits uncovered. Instances of unknown lapsed contribution occurs when employers inform their workers that their share of the contribution is paid but do not actually pay the premium continuously. An informal worker shared: 
"The continuity of payment depends on the [manpower] agency or employer. I thought my employer was continuously paying but I could not avail the benefits when I needed as my employer did not pay their share of the premium."

Informants recommend a tiered payment scheme for the informal workers wherein the government shares the burden of premium costs, similar to how formally employed workers share costs with their employer. Another proposal is a progressive scheme wherein informal workers with higher income pay a higher premium. They also prefer a quarterly schedule to reduce indirect costs of premium payment. Informants also suggest a text message scheme wherein a reminder is sent prior to the deadline of the current payment cycle to encourage continuous contribution. An informal worker stated:

"A customizable package for informal sector workers is preferred and should be custom fit to our capacity to pay. There should be a tiered payment strategy: the higher the income, the higher the premium paid."

\section{Discussion}

Attainment of UHC has been a key priority both in the Philippines and the global agenda of social protection. Governments usually rely on three strategies to increase health coverage: 1) a centrally managed and tax-financed national health care system, 2) development of social health insurance schemes, and 3) promotion of private health insurance (7). These strategies mostly target the sector of the population in the civil service or formal economy (8). In low- and middle-income countries (LMIC), attaining UHC is complicated by the large and continuously rising share of the population employed in the informal sector (2).

There is a gap in identifying or validating whether or not sponsored members are part of the informal economy or not. In theory, they are members who don't have the capacity to pay their premiums. However, there is still a question on whether or not they do not have the capacity to pay as the process of identifying such members may be affected by politics. This can result in underestimation of the informal economy workers. The informal sector is highly diverse and 
ranges from professionals to below-minimum wage workers (5). Knowing the size and scope of the informal sector is then crucial for policymakers to design appropriate policies and programs for their assistance and social protection (2).

Our results also show that a lack of awareness about $\mathrm{SHI}$ is a barrier to both enrollment and retention. In a 2013 South Africa study, 24\% of participants identified lack of awareness as the most important barrier to enrollment (9). In a 2017 Nigeria study, education was a consideration for varied awareness levels of a SHI (10). A systematic review published in 2012 that included 19 LMIC studies found that education increases a person's likelihood of enrollment (11). It is then likely that a person with higher educational attainment may better understand and comprehend the benefits of participating in a SHI (10). The better an individual understands the benefits of health insurance, the more likely they are to participate in the scheme (12).

This study found that unaffordability of the premium is a deterrent to enrollment and retention. Two studies in Kenya found that the premium amount was thought of by the informal sector as unaffordable and posits that, while some entities are able to afford the premium, substantial sections of the informal sector were unable to cope with this and would continue to require government subsidies to be included in the health insurance scheme $(13,14)$. In financing UHC, policy-makers should take into account whether the informal sector has the financial capability to participate in a prepayment scheme for health care (14). Wealthier individuals are more likely to participate in a SHI, so it is unsurprising that amount of premium payment is a determinant of enrollment and retention (12). The policy direction of expanding contribution collection to the informal economy is led by the assumption that the sector is the "missing middle" or that they have substantial financial resources that can be tapped to finance UHC (14). In an environment characterized by seasonal employment and high variations in income, informal workers are unable and even unwilling to pay premiums for SHI $(12,15)$. 
Interviews and focus group discussions reveal that informal workers find premium payments inconvenient, inaccessible, and result in income loss due to the indirect costs of payment. Frequent lapsed contributions also occur due to the seasonal and unprotected nature of informal work. Collecting premium contributions from the informal sector continues to be a challenge for many LMICs (16). More flexible terms of premium collection that adapts to local realities are considered the most appropriate approach compared to the one-size-fits-all model currently used by the Philippines $(12,17)$. The various preferences in payment schedule, mode, and location emphasizes the diverse priorities and needs within the sector. Purchasers in the Philippines must then determine the extent to which they can accept and accommodate irregularity of premium payment from the sector (12).

Another crucial set of factors identified in this study are on supply-side issues which includes the (perceived) quality of health care services and the benefit package offered by a SHI. In supply-side issues, many other factors may come into play: the state and proximity of a healthcare facility, availability of medical staff, waiting times, and availability of medicines, among others. A similar phenomenon was observed in Tanzania, where dropout was primarily related to the lack of quality care services and failure of $\mathrm{SHI}$ to meet the needs of the beneficiaries. In this case, respondents resorted to more convenient alternatives such as traditional medicines, private health facilities, and pharmacies (12). In Kenya, participants found benefit packages attractive and comprehensive on paper, but benefits received in practice was limited. This, coupled with poor bedside manners of health staff, ultimately led to attrition (13).

\section{Conclusion}

Informal workers are individuals who are not covered by protective labor laws and tend to not belong or contribute to a national health insurance scheme. In the case of the Philippines, the diversity of informal work and dynamic nature of the sector works against an ideal one-sizefits-all solution to increasing informal sector enrollment and retention to SHI. 
345 Due to the significant size and unorganized nature of the sector, it remains a significant 346 challenge to capture each individual segment that comprises its entirety. It may be more 347 significant to target individuals within the informal sector who have the ability to contribute and 348 pay premiums. Specifically targeting these individuals will enable the Philippines SHI to 349 allocate resources towards strategies that can create sustainability of the financial pool.

\section{Study limitations}

351 This study is limited by the underrepresentation of informal sector members from semi-rural 352 and rural areas. Only informal sector members connected to labor groups in Manila were 353 reached to take part in the study. The viewpoints of semi-rural and rural workers were then 354 not captured in the study.

355 The study also did not include informal sector workers in the high-income quintile. They may have provided insights that differed from those found in this study.

357 The study was unable to gather insights from representatives of other Philippine social 358 insurance agencies who may have been able to share their knowledge on informal sector enrollment retention for non-health social insurance schemes.

\section{List of abbreviations}

361

UHC - universal health care

LMIC - low- and middle- income country

SHI - social health insurance

\section{Ethical considerations}

This study received ethics approval from Corazon Locsin Montelibano Memorial Regional Hospital on 18 July 2019 with protocol number CLMMRH-RERC 2019-18.

\section{Availability of data and materials}


368 The datasets used and/or analyzed during the study are available from the corresponding

369 author on reasonable request.

\section{Competing interests}

371 This study was commissioned by the Philippine Health Insurance Corporation.

\section{Funding}

373 This study was funded by the Department of Science and Technology-Philippine Council for

374 Health Research and Development.

\section{Author's contributions}

376 DS Jr and TT participated in the research conception and design. RKS managed research

377 implementation. DS Jr, TT, GKR, and RKS participated in data collection. TT, GKR, and RKS 378 developed the topic guide. GKR and RKS conducted the analysis. RKS conducted the 379 interpretation of results. GKR and RKS drafted the results. RKS wrote the manuscript. All 380 authors reviewed the manuscript.

\section{References}

382 1. Handayani S. Social protection for informal workers in Asia. 2016.

383 2. Bitran R. Universal Health Coverage and the Challenge of Informal Employment: 384 Lessons from Developing Countries. Health, Nutrition, and Population (HNP) Discussion 385 Paper. 2014.

3. International Labour Organization. Transitioning from the informal to the formal economy. 2014.

4. Gonzales M. Size of the Informal Economy in the Philippines. In: Employment DoLa, editor. Manila2018. 
390 5. Philippine Health Insurance Corporation. Terms of Reference - Informal Economy 391 Segmentation Study: Towards UHC in the Philippines - Reaching and Retaining Members in 392 the Informal Sector. 2017.

393 6. Castleberry A, Nolen A. Thematic analysis of qualitative research data: Is it as easy as 394 it sounds? Currents in Pharmacy Teaching and Learning. 2018;10(6).

395 7. Gottret P, Schieber G. Health financing revisited: a practitioner's guide. 2006.

396 8. Alfers L, Lund F, Moussié R. Approaches to social protection for informal workers: 397 Aligning productivist and human rights-based approaches. International Social Security 398 Review. 2017;70(4):67-85.

9. Govender V, Chersich M, Harris B, Alaba O, Ataguba J, Nxumalo N, et al. Moving 400 towards universal coverage in South Africa? Lessons from a voluntary government insurance 401 scheme. Global Health Action. 2013;6(1).

402 10. Adewole D, Akanbi S, Osungbade K, Bello S. Expanding health insurance scheme in 403 the informal sector in Nigeria: awareness as a potential demand-side tool. The Pan African 404 Medical Journal. 2017;27(52). 11. Acharya A, Vellakal S, Taylor F, Masset E, Satija A, Burke M, et al. The impact of 406 health insurance schemes for Low- and Middle-Income Countries: A systematic review. The 407 World Bank Research Observer. 2013;28(2).

408 12. Verbrugge B, Ajuaye A, Ongevalle J. Contributory social protection for the informal 409 economy? Insights from community-based health insurance in Senegal and Tanzania. 2018. 
410 13. Barasa E, Mawaura N, Rogo K, Andrawes L. Extending voluntary health insurance to 411 the informal sector: experiences and expectations of the informal sector in Kenya. Wellcome 412 Open Research. 2017;2(94).

413 14. Okungu V, Chuma J, Mulupi S, Mclntyre D. Extending coverage to informal sector 414 populations in Kenya: design preferences and implications for financing policy. BMC Health 415 Services Research. 2018;18(13).

416 15. Kimani J, Ettarh R, Warren C, Bellows B. Determinants of health insurance ownership 417 among women in Kenya: evidence from the 2008-09 Kenya demographic and health survey. 418 International Journal for Equity in Health. 2014;13(27).

419 16. Mclntyre D. Health service financing for universal coverage in East and Southern 420 Africa. EQUINET Discussion Paper2012.

421 17. Sarker A, Sultana M, Mahumud R, Ahmed S, Islam Z, Morton A, et al. Determinants of 422 enrollment of informal sector workers in cooperative based health scheme in Bangladesh. 423 PLoS ONE. 2017;12(7). 